\section{CATARACT EXTRACTION WITHOUT IRIDECTOMY,}

THE CORTICAL MATTER BEING REMOVED BY INJECTION WITH A SPECIALLY CONSTRUCTED SYRINGE. 1

BY W. J. CANT, L. R.C.P. LoND. Sc., HONORARY SURGEON TO THE LINCOLN COUN'T HIOSPITAL.

For a period of over two years I have adopted the plan carriel out by Dr. McKeown of injecting water for the removal of cortical matter in cataract extraction, but recently with two modifications : - (1) By using what, in my opinion, is a more convenient syringe; (2) by not performing iridectomy. The nozzle of the syringe I use is much smaller in every way; it has no projecting lip, and can be introduced and manipulated in the eye without causing any discomfort to the patient. The body of the syringe is short, so
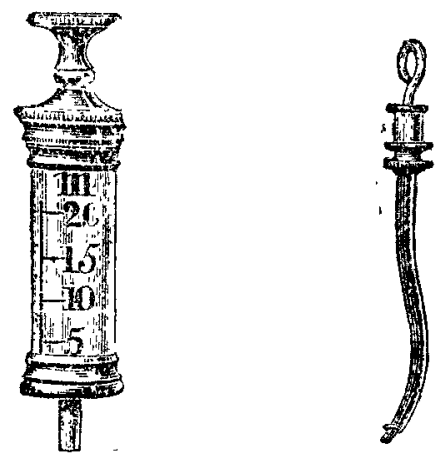

that the hand of the operator comes close to his work; and although it holds only about twenty drops, this is quite sufficient for ordinary purposes, but if necessary it can be cefilled. Messra. W. Wood and Co. of York are the makers of the syringe.

In the forty cases in which I have performed this operation there has been the greatest success. In none of the cases has there been any tendency to loss of vitreous, no iritis of any moment, and certainly less than in those where iridectomy was performed. This is due, I think, to the absence of any blood in the anterior chamber, and to the iris not being mjured. In a few cases the base of the iris has formed a slight adhesion to the wound, but the pupil has remained circular and active. I have never found any trouble caused by this ; it is of no more consequence, and occurs no oftener, than the slight adhesions that are sometimes seen when iridectomy has been performed. There were two cases of prolapse-one caused, I believe, by using eserine, which stretches the iris, so that the aqueous, not having means of free escape, forces it out in to the wound; the other occurred in a very restless patient. On both these cases iridectomy was done the day after under chloroform without any difficulty, as the wound is kept open by the prolapsed iris, and the result was the same as in the iridectomy cases. No intlammation followed, and the vision was good. The operation is carried out in the following manner, and I performed it on June 12 th Wefore the members of the Midland Branch of the British Medical Association:-A solution of homatropine and cocaine is dropped into the eye twice before the operation, so as to have the pupil fully dilated. It is then made anæesthetic with cocaine, and all the parts, toogether with the instruments, made antiseptic with a perchloride of mercury solu tion ( 1 in 5000), the patient being operated upon in his own bed. The eyeball is fixed with the forceps, and the eyelid raised by an assistant, or by the ring finger of the operator, and the ordinary linear extraction incision made with a Taylor's knife, which, having a broad base prevents the iris falling over the edge. After the section of the cornea has been made, the operator takes charge of the upper lid, introduces the cystotome, and freely opens the capsule. The lens is then gently pressed out with as much cortical matter as possible. During this, the iris prolapses well out of the wound, and the eye is then in the same condition as when iridectomy has been performed. The nozzle of the syringe is introduced, and warm water syringed into the lens cavity. Any cortical matter readily comes away,

I A paper read at the Ophthalmological Section of the British Medical Association beld in Birmingham, Aug. 31st, 1890 . the edges of the wound are thoroughly cleaned, the iris falls at once into its place with the help of the nozzle of the syringe used as a spatula. The iris then becomes contracted. A little perchloride solution is allowed to run over the eye ball, the lids closed and smeared with vaseline and atropine ointment, a hot wet pad of sal alembroth wool applied, and then gutta-percha tissue, dry wool, and a bandage. The patient is kept perfectly quiet for twenty-four hours, the eye dressed daily in a similar manner for four days, then a dry pad only.

I have performed this operation in cases where the lens was immature, where there was a large amount of white cortical matter, and in traumatic cataracts, seldom making any selection. In traumatic cataracts it is especially useful as the lens matter can be removed before inflammation occurs to fix the iris and increase the difficulties. In cases of steel in the lens, I have removed the steel with a magnet, and then the whole lens at once, with the best possible results. It is not necessary to do secondary operations so often, as, there being no iritis, there is no thick membrane formed. The vision, if anything, is better than when iridectomy has been done, as I have proved in patients who had been iridectomised in one and not the other eye and there are the other advantages of having a circular, active, and natural pupil.

Lincoln.

\section{INFLUENZA}

\section{Bx CHARLES HGERTON FITZGERALD, M.D.}

NoT long since THE LANCET published a short note of mine on "Influenza," in which I expressed the opinion that the so-called influenza was not a disease per se, but a profound modification by some unknown "influence" of any ordinary disease which might be present. Since I thus wrote I have had ample opportunity of witnessing and experiencing personally the course and symptoms of this disease, and am more than ever convinced of the truth of the view I then advocated. During the prevalence of the influenza wave I believe the atmosphere to be teeming with some pathogenic "influence," possibly (as it is the fashion nowadays to ascribe everything to microbic agency) to some germ or spore. Or there may possibly exist at such times some electrical state of the atmosphere, which may exercise an unknown but powerful influence on the nervous system. However it may originate, the whole atmosphere seems then to be laden or charged with somesubtle poison which profoundly modifies any existentillness. To my mind the whole history of the influenza epidemic points to the truth of this theory. I would ask, What are the symptoms of influenza? They are so numerous and so protean that it is simply impossible to ascribe them all to any one disease. Every organ in the body is in turn affected-the brain, the spinal cord, in fact the entire nervous system. In other cases it is the beart and circulation. the respiratory tract, the bowels and digestive organs, the muscles or the joints which are affected. There is no uniformity about the symptoms; in scarcely two cases are they alike. Take, for example, the temperature ; it is sometimes high, sometimes subnormal, sometimès normal. Nor is there less variation in the pulse; it may be rapid, slow, strong, or weak; arterial tension may be increased or diminished. Catarrh may be absent or present, there may be diarrhoea or constipation, prostration or excitement. Perhaps the most general symptom is a passive inflammation of the base of one or both lungs, which generally (not always) clears away rapidly. Again, look at the sequelæ ascribed to influenza, they are at once so diverse and so multitudinous that it seems folly to consider them all as the result of any one complaint. It is scarcely possible to take up a number of THE LANCET without neeting with some new sequela of this protean disease. Paralysis, meningitis, neuralgia, herpes, heart failure, valvular disease, muscular weakness, rheumatism, arthritis, dropsy, alopecia areata, eczema, jaundice, diabetes, albuminuria, dysentery, abortion, these and a host of other maladies, due to disturbance of every individual organ in the body, all are put down to one single cause. It seems to me in the highest degree unphilosophical and absurd to credit any single disease with so varied a train of symptoms and sequelæ. A far more rational solution of 
the difficulty is found if we. imagine the whole system, especially the nervous system, to be deeply impressed and lowered by some powerful external agency, which renders it not only prone to succumb to any illness, but aggravates and deepens the ordinary symptoms of any disease the patient may contract. I cannot help fancying some vague idea of this truth must have originated the Italian name influenza-i.e., an "influence," exercised by some unknown cause on all illness occurring at certain seasons or under certain atmospheric conditions. The frequency with which attacks, which at any other time would have been only ordinary catarrh, bronchitis, or indigestion, assumed a grave character and an adynamic type, was especially remarkable during this epidemic. So general, indeed, was pneumonia (mostly double) as a symptom, that I was at one time disposed to regard it as the epidemic. I am quite sure I saw more cases of double pneumonia during the three months when influenza prevailed than $I$ had treated in the previous twenty years. All these facts, I submit, point rather to some powerfnlly depressing atmospheric or aerial agency than to any ordinary infection or contagium.

What this "influence" is $\mathrm{I}$ am unprepared to say, but I am convinced we are more likely to arrive at a philosophical and practical comprehension of this mys. terious epidemic by studying and working on the lines I have here imperfectly indicated than by regarding influenza as a separate entity.

Folkestone.

\section{ECTOPIC OVARIAN GESTATION.}

\section{BY H. A. REEVES, F.R.C.S.ED., M.R.C.S.,} SURGEON TO THE HOSPITAL FOR WOMEN ETC.

For the notes of this uncommon and interesting case I am indebted to Mr. C. E. May, house surgeon to the hospital.

C. $\mathrm{M}-$ aged thirty-seven, married seventeen years, has had four children and one miscarriage; last pregnancy twelve years ago. Catamenia began at fifteen, always regular. She was admitted by Dr. J. Oliver complaining of pain from a pyriform tumour situated centrally, which was smooth, tense, elastic, but not fluctuating, and very prominent anteriorly. The growth was movable laterally, painless, and dull. Vaginal examination revealed that the cervix did not move with the tumour, but that it was soft. No fotal, placental, or uterine sounds or ballottement. She stated that she thought herself pregnant, and miscarried in May, 1889. At this time she flooded and passed clots, and was in constant pain, and after this was in St. Bartholomew's Hospital under the late Dr. M. Duncan for ovarian inflammation. Before this supposed miscarriage she missed two periods. From May till December theimenses disappeared, and as her abdomen was getting gradually larger, she thought herself pregnant and engaged a medical man to attend her. On Dec. lst last year she began to lose blood and the flow con. tinued for eight weeks, but the loss was not very profuse. She again lost blood for a week, just before the operation, near the end of April of this year. Her abdomen was larger at Christmas than it was in April, 1890 , but has again increased in size during the past three or four months. She says she felt foetal movements in October and November, and that the swelling caused her pains which were like labour pains. In November she had a sudden attack of abdominal pain, lasting fifteen minutes, and nearly fainted, but has had none since. No sound was passed till after the menstruation which preceded the operation, when it was found that the uterus was enlarged, as the sound passed three inches and to the left. A whitish watery secretion could be expressed from the breasts, which were not enlarged. Montgomery's glands seemed prominent. At a consultation three probabilities were discussed - viz., ovarian with pregnancy, fibroid with same cordition, and extra-uterine gestation, and it was decided to explore and act according to conditions.

On opening the abdomen a large tumour, having the aspect of uterine tissue with patches of inflammation, and which by its feel might have been a fibro-cyst or even a pregnant uterus, was exposed. On introducing the hand the enlarged womb, which was not bicornuate, was found at the lower and right portion of the tumour. A mediumsized trocar was introduced into the growth, and about three ounces of yellowish, thick, and foul-odoured fluid withdrawn. The end of the instrument struck against a hardish body, and as no more fluid escaped the trocar opening was slightly enlarged and the finger introduced. The shoulder and head of a foctus were then felt, and the wound in the sac was enlarged by carefully tearing it with the two index fingers, and the deal child extracted. The cord was then clamped and divided. The macerated placenta, which was of yellow aspect, was peeled off the inside of the sac without bleeding. The broad ligament was then tied in a double ligature close to the uterus, and the thickened remains of the foetal membranes peeled away. The placenta was inside the fotal membranes, which were enclosed between the layers of the left broad ligament, and the normal-looking Fallopian tube was stretched across the upper and anterior aspect of the tumour. No trace of the left ovary could be seen or felt, and in peeling off the membranes, which were firmly adherent in places, a portion of the posterior layer of the broad ligament corresponding to the usual position of the ovary was removed with them. The right ovary was cirrhotic, and was left. The pedicle was treated intra-abdominally, and a glass drainage-tube was passed through the rent in the posterior layer of the broad ligament, so as to drain the cavity occupied by the tumour between its layers after the rent edges were attached to the parietal peritoneum. The tube was removed early on the third day, as nothing came through it after thirty-six hours. Her temperature never exceeded $99^{\circ}$ or the pulse 100 , anci she was in the general ward on the sixth day.

I think there can be no doubt that this was a genuine case of true ovarian pregnancy-not tubo-ovarian, - and that the growth first separated the layers of the mesovarium and expanded between the layers of the broad ligament. The normal. looking Fallopian tube was stretched over the tumour, and not the slightest trace of ovarian tissue could be seen or felt, being probably encroached on and absorbed by pressure during the development of the fotus, which looked like a full term one, and was a female. The uterus was not bicornuate even in a rudimentary sense, and the reddish aspect of the tumour was most likely due to the hypertrophied unstriped muscle fibres between the layers of the broad ligament. The foetus and other parts removed have been kept, and are open to inspection by anyone interested. According to the patient's history she became pregnant in March, 1889, and two months after the real or supposed miscarriage occurred. May it not be that she was carrying twins, one in the womb and the other in the ovary, and that she aborted the former? or was, as may be more likely, the uterine hæmorrhage decidual only, and in connexion with the ectopic pregnancy? She felt quickening movements at the seventh and eighth months, and at these dates had spurious labour pains. In. November-i.e., at end of the eighth month-the sudder. attack of severe pain was probably due to the death of the child, but it must not be forgotten that these pains may have been caused by the contraction of the walls of the sac or by those of the womb. At the ninth month she had flooding, which lasted, though not profusely, for two months, and again seven weeks after she menstruated (?) for a week. Was the bleeding at the ninth month decidual, or was it merely from an enlarged and congested womb? I think it must have been the former. Her abdomen, which was large in December (ninth month), decreased in size, doubtless because of the absorption of liquor amnii ; but it is not easy to account for her statement that it again increased in size, unless one supposes that the tumour, from being more or less lateral, became central and projected more, or that the attacks of inflammation of which the serous sac wall gave evidence caused intestinal distension, thus misleading her. There were anterior parietal adhesions, and the posterior layer of: the broad ligament was adherent to the sigmoid flexure. Grosvenor-street, $\mathrm{W}$.

ACCOMMODATION FOR THE INSANE POOR - In connexion with a letter from the Commissioners in Lunacy, the Asylums Committee of the County Council in their report recommend: "That they be authorised to take such preliminary steps as they think best for promptly providing. further asylum accornmodation for 2000 lunatics, provided that no engagement or liability be entered into without the. sanction of the Council." Mr. Boulnois, M.P., hoped the matter would be postponed for consideration for six months: in order that they might obtain fuller information. Some. discussion followed, and the recommendation of the committee was agreed to. 